Revista Aspas

ppgac - USP

Artigo

\title{
PARÂMETROS FENOMENOLÓGICOS PARA PESQUISA QUALITATIVA EM ARTES CÊNICAS
}

\author{
PHENOMENOLOGICAL PARAMETERS FOR \\ QUALITATIVE RESEARCH IN SCENIC ARTS
}

\author{
PARÁMETROS FENOMENOLÓGICOS PARA LA \\ INVESTIGACIÓN CUALITATIVA EN ARTES ESCÉNICAS
}

\section{Carlos Alberto Silva}

Carlos Alberto Silva Doutor e Mestre pelo Departamento de Artes Cênicas da Escola de Comunicações e Artes da Universidade de São Paulo (ECA-USP). Instrutor de atividades infanto-juvenis no Sesc. Formador de professora(e)s em linguagens artísticas. 


\section{Resumo}

Este artigo é a primeira parte de um ensaio cujo objetivo é expor o emprego de alguns parâmetros do método fenomenológico de pesquisa qualitativa, estruturado para um estudo sobre a operacionalidade do gesto cênico e que constituiu minha tese de doutorado no âmbito do programa de pós-graduação da ECA-USP, a qual foi editada pela Nova Editora Acadêmica com o título Operacionalidade do gesto poético: do cotidiano à cena. Nesta etapa são abordados, em particular, aspectos epistemológicos que fundamentam o método, bem como alguns procedimentos que pontuam o trânsito entre noções teóricas e articulações práticas na estruturação metodológica para orientar a percepção, o registro, a organização e a análise de dados, que derivaram do acompanhamento de performances cênicas envolvendo três atrizes em processos criativos de diferentes montagens.

Palavras-chave: Epistemologia, Método, Fenomenologia, Artes Cênicas, Géstica.

\section{Abstract}

This article is the first part of an essay that aims to expound the use of some parameters of the phenomenological method of qualitative research, that was structured for a study about the scenic gesture's operationality which built my $\mathrm{PhD}$ thesis at the postgraduation program of ECA-USP, and was edited by Nova Editora Acadêmica, under the title Operacionalidade do gesto poético: do cotidiano à cena. At this stage there will be displayed, particularly, epistemological aspects that compose the method, and some procedures that point to a flow between the theoretical knowledge and practical articulations in methodological structure to guide data perception, registering, organization and analysis, that derived from scenic performances following-up with three actresses in creative process of different constructions.

Keywords: Epistemology, Method, Phenomenology, Scenic Arts, Gestic. 


\section{Resumen}

Este artículo es la primera parte de un ensayo que busca exponer el empleo de algunos parámetros del método de investigación cualitativa, estructurado para un estudio sobre la operatividad del gesto escénico y que constituyó mi tesis de doctorado en el programa de postgrado de la ECA-USP, la cual fue editada por Nova Editora Acadêmica como Operacionalidade do gesto poético: do cotidiano à cena. En esta etapa se abordarán, en especial, aspectos epistemológicos que se basan en el método, así como algunos procedimientos que marcan la relación entre los aspectos teóricos y las articulaciones prácticas de la estructuración metodológica para orientar la percepción, el registro, la organización y el análisis de datos, que se originaron de la observación de performances de tres actrices en procesos creativos de diferentes montajes.

Palabras clave: Epistemología, Método, Fenomenología, Artes Escénicas, Géstica.

Aqui serão expostas reverberações de um processo de pesquisa sobre a operacionalidade do gesto em cena, cuja parte central foi acompanhar criticamente trechos de performances teatrais nas relações pertinentes ao gesto cênico.

O desafio de eleger bases metodológicas adequadas para inspirar as observações e os encaminhamentos de coleta e análise de informações nessa área de conhecimento, frequentemente arredia a ofertas estranhas a sua esfera, foi resolvido durante o percurso. Aos poucos descobri que essa dinâmica responde, inclusive, às demandas do método que norteou a investigação.

Por um lado, é ineficaz, e quase impossível, o emprego direto de metodologias de outras áreas; por outro, não temos disponíveis, ainda, metodologias autônomas dentro das artes da cena. Por isso, parece ser ineficiente nos fixarmos estritamente do lado de dentro. Um intercâmbio é tanto imprescindível quanto desejável.

No caso da pesquisa que serve de referência às considerações aqui expostas, tanto pelas pendências metodológicas como pela natureza de seu objeto, foi incontornável circular por diferentes campos de saberes. 
De todo modo, não raro, estudos em artes adequam-se à rotina acadêmica, lugar singular desse tipo de atividade. Talvez pensar a autonomia metodológica devesse começar por aí. Diante do argumento de que tal rotina não é um método stricto sensu, pode-se contrapor que condiciona caminhos percorridos. Isso se refere à formatação do "projeto de pesquisa" que, com pouquíssimas variações, é efetuado de modo quase uniforme, qualquer que seja a esfera de saber. É um modelo vastamente usado e o conhecimento produzido no âmbito acadêmico é pautado por essa rotina, na qual são acomodadas as intenções de estudo e nunca o contrário. O método que será comentado propõe reciprocidade entre ambas.

Vinculada à menção sobre a observância desses padrões, apresenta-se a validação de resultados. A construção de conhecimento, mesmo com as formalidades impessoais, parece mais calcada em concordâncias, cumplicidades, pactos, propensões e crenças do que a objetividades. Arriscaria que até o suposto rigor das ciências ditas exatas cede a esse comportamento. Que dirá nas artes! Admitir resultados de pesquisas como coerentes depende dos parâmetros eleitos para sua organização.

Objetividade seria, portanto, uma concordância firmada sobre algo entre determinada quantidade de subjetividades que atinge certa supremacia, isto é, uma comunidade que reconhece resultados como justos e, assim, não contestam os procedimentos para tal consagração.

Um enunciado qualquer, dentre os muitos que encontramos em diversos suportes, pode ser um axioma, um postulado ou a conclusão de um desenvolvimento argumentativo. No último caso, há de se definir uma epistemologia a partir da qual os argumentos são estruturados. Mas a maneira simplesmente assertiva encerra a aceitabilidade da, também simples, negação. E assim se encerram possíveis diálogos.

Ouvi muitas vezes pareceres como: "eu não gosto do uso de tal termo", dados por integrantes de bancas examinadoras e palestrantes nas áreas artísticas. Mesmo em respeito à posição de quem assim julga, seja lá pelo motivo que for, é um tipo de postura que deixa lícita a réplica: "pena que nossos gostos não coincidam". A conversa poderia se encerrar aí e o parecer sobre um longo trajeto de reflexão ficaria restrito a diferenças de predileções. 
Há que se escapar dessa situação pela via da consistência de argumentos.

A integridade de quem pesquisa deve depor a favor da "democracia do saber", isto é, como diz Gondim e Lima (2010, p. 21), "o saber vale por sua própria fundamentação, e não pela reputação da pessoa que o produz" - eu acrescentaria: origem racial, ideologia, condição etária, gênero e tantos outros aspectos que vemos, cada vez mais, se suplantar ao nexo do que é proferido o que tem como consequência que a atitude pesquisadora radical deseja expor resultados à crítica. Acredito que o mesmo deve valer ao ato de criticar.

Se admitirmos que a pesquisa científica objetiva fundamentalmente contribuir para transformações dos saberes humanos, sendo sistematicamente planejada e executada segundo critérios de processamento de informações, então nos resta verificar e ajustar quais são esses critérios. Porém, antes de dar cabo a essa etapa é preciso discernir como e de onde surgem e de que maneira são arranjadas essas informações.

Revolvendo saídas epistemológicas para resolver esses impasses, fui atraído por um aparente paradoxo expresso como empírico-apriorístico.

Por um lado, o conhecimento enraizado na experiência, na apreensão do mundo pelos cinco sentidos; ou do âmbito subjetivo, pela introspecção, não por isso menos aliado à experiência. De uma maneira ou de outra, tal noção promove saberes valorizando métodos cuja cientificidade provém de recursos empíricos. Esses, por outro lado, em tese, colidem com um modelo de entendimento que independe da facticidade, já que é gerado no interior da própria razão que demonstra um fenômeno usando argumentos tomados a priori, que se bastam. Em seu estado "puro" parte, portanto, de convicções escoradas em artifícios apenas intelectuais a respeito da existência, isto é, de modo apriorístico.

Sem entrar no mérito filosófico mais agudo, o pretenso oximoro atualiza que o conhecimento corporeado, tal como defendido pela fenomenologia, é engendrado pelo que é dado à totalidade corpo-mente saber e compor em si. Portanto, sem nenhum a priori que não a própria existência. Mas, como seria o estabelecimento de procedimentos de descobertas e de formulações sem absolutamente nenhum a priori? Não seria, acaso, o corpo com suas formações, informações, deformações e condições perceptivas já um a priori para o saber, ao menos diante do conceito da totalidade corpo-mente? 
Por outro lado, como é possível conhecer algo com o que não se teve rigorosamente nenhuma experiência? À razão seria dado falar apenas de si, e nada mais. Como é possível pensar e versar sobre algo que nunca foi visto, ouvido, cheirado, degustado e sentido epidermicamente? Como refletir sem nenhum grau de facticidade?

Assumir uma conduta empírico-apriorística foi uma condição do aprendido no decorrer da busca por verificações.

Dessa forma, para solucionar as questões pertinentes ao trabalho com as informações me percebi imerso num jogo entre caminhos empíricos e apriorísticos. Esse convívio com um entendimento epistemológico, digamos, simbioticamente híbrido me fez desembocar no método fenomenológico de pesquisa qualitativa, que propõe procurar diferentes metodologias para diferentes tipos de participantes, objetivos, situações e assuntos.

Essa orientação para pesquisa sugere identificar experiências compartiIhadas com vistas a localizar características generalizantes. Ou seja, é sempre uma tentativa de reconhecer atitudes e procedimentos comuns a vários indivíduos que experienciam o mesmo fenômeno. Considerar a experiência inclui eventos, como foram experienciados e formulações da essência da experiência.

A abordagem investigativa da fenomenologia abrange três elementos: estudo das experiências vividas por pessoas, experiência como processo consciente e desenvolvimento de interpretações dessas experiências.

Nos limites deste artigo não é viável exemplificar como e onde na pesquisa de referência os critérios do método dialogam com os conteúdos, nem expor as etapas do método a serem seguidas. Nesse contexto, é muito mais relevante ponderar aspectos que as fundamentam. Além disso, consultar tais etapas alhures não é tarefa difícil, embora exija um investimento razoável de tempo.

Para que a consistência metodológica não seja descuidada, é cabal manter o foco do método fenomenológico de pesquisa qualitativa e não se limitar a preencher modelos. São apontados apenas itens que conduzem o empenho em preenche-los, mas que não bastam. É mister atentar para que, no desenrolar da pesquisa, quando for o caso, as orientações sirvam para guiar a navegação quando o navegante imergir em turbulências. Assim, é difícil estipular que etapa precedeu qualitativamente outra. Não foram raras as ocasiões em que o conhecimento de determinados parâmetros metodológicos 
foi posterior a outras partes do estudo e confirmaram uma intuição e/ou confortaram um desvio de rota.

Assim, parece ser mais procedente apresentar ao menos algumas inspirações epistemológicas e teóricas com as quais os referidos critérios se relacionam.

De início, proponho ponderações sobre os termos "experiência" e "narrativa", essa normalmente vinculada à memória e à metáfora. Eles se relacionam tanto à perspectiva empírico-apriorística como às linhas epistemológicas e teóricas que dão origem à formulação do método em foco pautado na fenomenologia de Merleau-Ponty, na Gestalt e nas ciências cognitivas. Tornamse, assim, construtos fundamentadores.

Merleau-Ponty (1908-1961) critica a premissa cartesiana que sobrepõe representações do mundo ao próprio mundo como fundamento de toda atividade cognitiva e mesmo perceptiva. Ainda que defenda a simbolização como postura que permite transcender uma dada realidade pelo distanciamento, o que impugnaria sua crítica ao cartesianismo, posiciona-se pela defesa da retomada da experiência como retorno ao fenômeno ao afirmar que tudo o que sabemos do mundo, mesmo no campo das ciências, sabemos a partir de uma visão ou experiência própria sem a qual os símbolos não diriam nada. (MERLEAU-PONTY, 1999).

A experiência é vista, nesse sentido, como vetor para o método. Por isso, é clarificante notar o entrelaçamento de diferentes linhas etimológicas do vocábulo "experiência." Ele deriva do indo-europeu per, que significa literalmente "tentar, aventurar-se, correr riscos." Já Victor Turner (1920-1983) frisou a origem grega perao, "passar por", que evoca os ritos de passagem (TURNER, 1982a).

O conceito de experiência emerge e passa a ser empregado nesse enquadramento a partir das concepções fundamentadas por Edmund Husserl, que o utiliza com mais frequência na variante de Erlebnis, em especial, nas Meditações cartesianas. Depois, Heidegger tratará dessa noção pensada também no sentido de Erfahrung.

Muitos autores dão continuidade à proposição fenomenológica da experiência como retorno ao fenômeno e fundamento ontológico de qualquer descrição como possibilidade de o ente humano transcender as aparências a partir da experiência. 
Entre eles, Varela, Thompson e Rosh (2003 apud MARINI; TOFFOLO, 2009) que, ao abordarem cognição criticamente, a descrevem de modo a entender o conhecimento na experiência cotidiana do viver, sobretudo, por meio da noção de enação', sempre como cognição corporificada e ação situada.

Desde a década de 1960, pode-se dizer, assistimos à contínua abertura a diferentes objetos epistêmicos, oriundos dos saberes cotidianos, do senso comum, dos jogos de linguagem e dos sistemas de ação.

Assume-se, assim, uma construção epistemológica que aceita a produção de conhecimento empreendido por profissionais específicos e não apenas por teóricos e intelectuais. Seria, então, um vetor que aponta para a noção de saber e que, admitida de modo amplo, engloba conhecimentos, competências, habilidades (ou aptidões) e atitudes, isto é, aquilo que foi chamado de saber, saber-fazer e saber-ser (TARDIF; LESSARD; LAHAYE, 1991; TARDIF, 2000).

Admitir que práticas e saberes profissionais engendram dinâmicas de conhecimento situado promove a perspectiva metodológica para acompanhamento de processos cênicos sob diferentes ângulos. $O$ fruto desses processos, potenciais temas de pesquisas, implica profissionais atuantes, que devem ser assumidos também como sujeitos. É fundamental descobrir como considerar o conhecimento situado emergente da relação entre os papéis envolvidos no estudo.

A cognição situada amplia as convicções da cognição corporeada, já que para esta tudo acaba em operações cerebrais e para aquela o cérebro não é o único lugar de conhecimento: reconhece uma interação dinâmica entre corpo, mente e mundo. Nesse sentido, a cognição se estende para além do sujeito. Assim, a cognição situada é estabelecida a partir de áreas centrais, mas não únicas nem exclusivas: articuladas em pensamento sistêmico,

1. Enação é um termo cunhado pelos biólogos chilenos Humberto Maturana e Francisco Varela (1980 apud VARELA; THOMPSON; ROSH, 2003), a partir da expressão espanhola enacción. A enação pode ser compreendida em dois pontos congruentes e complementares: 1. A ação guiada pela percepção, ou seja, a compreensão da percepção é a compreensão da forma pela qual o sujeito percebedor, através da estrutura sensório-motora, consegue guiar suas ações na situação local. A percepção não é mais um mundo dado anteriormente. 2. A cognição emerge dos esquemas sensório-motores vivenciados que permitem à ação ser construída e guiada pela percepção. É a estrutura vivencial sensório-motora contextualizada, a maneira pela qual o sujeito percebedor está inscrito num corpo. 
cuja concepção da natureza do aprendizado é prismática. Cultura, portanto, apresenta-se como um fenômeno dependente dos sistemas que a contêm: sociedade, estrutura orgânica e natureza inorgânica.

Um esboço feito de poucos e curtos traços de algumas linhas das teorias do conhecimento localiza melhor a cognição situada mediante a corporeada.

Após a dissolução kantiana das teorias metafísicas, no século XIX, e da ascensão do positivismo, a epistemologia assume, aos poucos, o estatuto de teoria da ciência e, a partir do pensamento empirista, torna-se uma reflexão normativa que busca estabelecer critérios de demarcação entre "a ciência e a não ciência".

O positivismo se distancia, entre outras proposições, do contexto de descoberta e das mudanças sociais que afetam as transformações de paradigmas capazes de abarcar a atividade científica. Esse fato se acentua pela associação ao desenvolvimento da sociologia das ciências e a diversos estudos sobre o conhecimento do senso comum, oriundos da etnometodologia, do interacionismo simbólico e da sociologia cognitiva, bem como do linguistic turn.

Além disso, a epistemologia se liberta do estudo estrito da lógica científica e contempla a história das ciências, a psicologia, a sociologia e a antropologia das ciências, sem falar de pensadores mais radicais como Derrida, Lyotard ou Foucault, questionadores agudos da racionalidade e autonomia científicas, esforçando-se em apontar a conivência delas com diferentes formas de poder: quem desobedece a normatividade acadêmica que, mesmo soando paradoxal, desconfia da atitude especulativa, por exemplo, deve se preparar para as consequências.

Consoante a essa noção está o pragmatismo, para o qual conhecimento é transformação interna através de atitudes e comportamentos. Afirma que o aprendido é subjetivamente interpretado e assimilado, o que conduz a uma mediação filosófica de cognição como processo pelo qual o conhecimento é ativamente construído.

A vertente construtivista da ciência cognitiva concebe pessoas criando conhecimento como resultado da interação entre crenças fixadas e novas ideias, enfatiza que nem o cérebro nem o indivíduo são locais determinantes de comportamentos. A mente é definida como um sistema que vai além do 
cérebro de um ser. Em contraposição ao realismo metafísico a cognição é adaptativa e serve para organizar o mundo experienciado. Nesse campo há ainda a destacar a interação entre indivíduo e sociedade, enfatizando ambiente de aprendizado, pessoas com quem o aprendiz interage, comunicação interpessoal e ação em grupos. Esse modo de conceber dinâmicas cognitivas ficou conhecido como interacionismo simbólico. O foco é a construção da identidade pessoal a partir da interação de indivíduos pela comunicação linguística. Significados são construídos socialmente e se inter-relacionam com e em ações.

Nesse contexto, tomamos da teoria da Gestalt, outro vértice epistemológico que sustenta o método adotado, a convicção de Christian von Ehrenfels (1859-1932): o todo é uma realidade diferente da soma de suas partes. Portanto, admite duas possibilidades: a totalidade e a somatória como realidades possíveis e, ainda, numa dada totalidade as partes não são sistemicamente mais o que eram quando separadas, e isso sem perder suas características fundamentais.

Para a Gestalt, a consciência tem a capacidade de captar os objetos na sua totalidade e em seu conjunto, pois nossa percepção dos objetos não se dá em partes ou fragmentos cuja junção seria efetuada posteriormente, isto é, não é pela reconstituição e associação de sensações isoladas que se tem a apreensão do objeto (GINGER; GINGER, 1995). No entanto, captar eventos em sua totalidade é uma possibilidade, já que à consciência é dada uma apreensão dessa natureza, o que não significa que necessariamente o faça.

$\mathrm{Na}$ teoria da Gestalt o todo é um conjunto indivisível de elementos distintos organizados como estrutura, na qual repousa a harmonia absoluta desses, de acordo com princípios consistentes de relações e inter-relações. Segundo Ginger e Ginger (Ibid.), a Gestalt estuda a percepção e as relações do organismo com seu meio. Paralelamente, as ciências cognitivas introduzem o conceito de affordance: o organismo no ambiente é uma relação recíproca-contextualizada.

Um postulado fundante da Gestalt é que todo campo perceptivo se diferencia em fundo e forma, ou figura. Assim, a percepção depende, ao mesmo tempo, de fatores objetivos e subjetivos, cuja importância relativa pode 
variar e se estabelece em relações dialéticas entre sujeito e objeto. Portanto, todo fenômeno é uma inter-relação global entre o ele próprio e seu meio momentâneo, incluindo o observador. A busca não deve incidir sobre as coisas (ou seres), mas sobre as relações entre as coisas (ou seres), porque o sentido emerge tanto do texto quanto do contexto (GINGER; GINGER, 1995).

Outro desafio que caminha junto com as fundamentações teóricas na configuração metodológica é detectar quando, e/ou se, um fenômeno observado foi percebido, ou se ganha essa condição ao se tornar consciente para alguém. Experiências, na acepção fenomenológica, seriam percebidas, se tornariam conscientes e originariam enunciados sobre elas.

Para Merleau-Ponty (1999) a percepção é a forma originária e primeira do conhecimento. Mas seriam percepção e consciência a mesma coisa? Se sim, então não haveria diferença entre percepção, consciência e conhecimento. E mais: como se relacionam com pensamento, linguagem e cognição? Segundo Freud (1987), existiria outro estado de consciência que não o de alerta, no sentido de uma intencionalidade inconsciente.

No cruzamento dos percursos epistemológicos seguidos, chegamos à noção de que o espírito não orienta o corpo para a apreensão de um objeto. Nosso corpo não responde nem a um automatismo cego nem é consciência clara. O corpo é natureza na medida em que é dependente do domínio biológico. Entretanto, transcendendo essa imposição, ultrapassamos a fronteira animal, instituímos níveis de ordem simbólica, transformamos o mundo, criamos e recriamos culturas.

Quando, por um lado, a imediatez pré-reflexiva é afirmada, não há distinção entre ato e pensamento, o que implica que não há distanciamento que faculte leituras feitas por trás das aparências. Por outro lado, a distância é fundada pela maleabilidade existencial e poética que carregamos.

A afirmação da fenomenologia merleau-pontyana de que simbolizar nos permite transcender uma situação, antecipando nosso futuro através da intenção, depõe a favor do argumento do humano não vir dotado de uma conduta preestabelecida e encara o corpo como expressão e convergência de intenções, desejos e projetos. 
Ser capaz de simbolizar significa poder formular enunciados sobre experiências e vai ao encontro do eixo metodológico da narrativa. Na perspectiva construtivista, conforme Viotti (informação verbal)22, o aspecto dinâmico da memória, da narrativa e da teorização destaca a relação entre funções neurais, processamento de informação simbólica e visões sociais, o que faz da lembrança uma atividade, já que reconstrói e reativa maneiras de pensar, ver, ouvir e fazer. Dessa forma, a narrativa tem um papel central na construção do self como forma representacional que transcende conceitos individuais e entende-la requer pensamento sistêmico, o que implica em semiocepção, isto é, um terceiro termo entre semiose ${ }^{3}$ e percepção. $O$ conhecimento é sempre relacional e, como consequência, narrativa, sensorialidade e gestualidade formam uma totalidade.

Dessa totalidade participa um dos horizontes abertos pela fenomenologia que agrupa reflexões, estudos e pesquisas pertinentes à metáfora. Ela, além de compor esse sistema, atua como geradora e resultado. George Lakoff e Mark Johnson (2002) demonstram que - e como - a metáfora está imersa na vida cotidiana. $\mathrm{O}$ aparato conceitual que desenvolvemos é fundamentalmente metafórico por natureza, e é por meio dele que pensamos e agimos.

A metáfora propicia três níveis de corporeamento de conceitos: o neural (domínio biológico), a experiência fenomenológica consciente (enunciação) e o inconsciente cognitivo (uma consciência fora do estado de alerta); e, tal qual o sistema conceitual humano, ela é um sistema estruturado, definido e sistematizado, por isso deve ser tratada também como conceito metafórico.

O significado metafórico advém, sobretudo, da memória, geralmente formulada em paradigmas de experiências, além da possibilidade de seu sentido derivar de uma única estrutura conceitual.

A síntese desse percurso pode ser expressa pela concepção de que não haveria linguagem em si, mas linguagem em situação, porque não há ser-em-si,

2. Informação obtida em aula da professora Evani Viotti da Faculdade de Filosofia, Letras e Ciências Humanas da Universidade de São Paulo (FFLCH-USP), em São Paulo, no dia 7 de março de 2013.

3. Termo que designa qualquer processo de significação, ação ou influência para sentido comunicante dado pelo estabelecimento de relações entre signos que podem ser interpretados por uma audiência. 
mas ser em situação (MERLEAU-PONTY, 1999). Esse ser em situação protagoniza cognição situada, que amplia a corporeada, calcada epistemologicamente nos saberes profissionais cultivados na, pela e com a experiência.

Assim, é preciso atentar para o fato de que a escolha e a delimitação do objeto de estudo também estão à mercê de uma condição metodológica que nos dirige e auxilia na avaliação do recorte do objeto diante da viabilidade de execução da investigação.

No que diz respeito às linguagens artísticas e às artes da cena em particular, os saberes se desenvolvem em seu contexto real de trabalho, em situações concretas do fazer, são compartilhados e transmitidos por meio de diferentes formas não restritas a uma única linguagem. Não seria exagero reconhecer a linguagem teatral como um lugar privilegiado de constituição cognitiva multimodal.

Assim, sugiro trazer para o universo das investigações em artes cênicas uma noção emprestada da sociologia:

as estreitas relações entre teoria, metodologia e prática de pesquisa, indicam que a sociologia não pode ser confundida com discurso filosofante, isolado de problemática empírica. Tal discurso, frequentemente, apoia-se apenas em uma linguagem grandiloquente, desprovido de qualquer fundamento, inclusive filosófico. $O$ trabalho tampouco deve ser confundido com mera manipulação de dados, destituída de fundamentos. Teoria e empiria são constitutivas da disciplina; uma não deve existir sem a outra. (GONDIM; LIMA, 2010, p. 9)

Quando um trabalho acadêmico trata de projetos específicos, o caminho aceito, desejado e costumeiramente indicado é normalmente o da narração e explicitações de processos idiossincráticos. Porém, quando a pesquisa diz respeito a princípios, concepções, conceitos e técnicas de um campo de conhecimento que transcendem singularidades, acredito que seja lícito que se reivindique compreensões mais amplas, detalhadas e consistentemente argumentadas.

Passar tudo pelo crivo de argumentações, como um jogo cujas peças são continuamente estruturadas, arranjadas e rearranjadas, demanda um caminho para encontrar as estratégias adequadas a cada situação, um 
modo de execução que está intrinsicamente vinculado àquilo que se elege para apurar.

Nos limites disponibilizados para este artigo, considero esboçada a introdução de um ensaio a ser aprofundado e ampliado ao tratar de outros procedimentos metodológicos, que incluem diferentes etapas da rotina de pesquisa e exemplos concretos a partir do trabalho tomado como base para estas reflexões.

\section{Referências bibliográficas}

FREUD, S. Sobre a psicopatologia da vida cotidiana. Rio de Janeiro: Imago, 1987. (Edição Standard Brasileira das Obras Psicológicas Completas de Sigmund Freud. v. VI).

GINGER, S.; GINGER, A. Gestalt: uma terapia de contato. Tradução Sonia de Souza Rangel. São Paulo: Summus, 1995.

GONDIM, L. M. P.; LIMA, J. C. A pesquisa como artesanato intelectual. Considerações sobre método e bom senso. São Carlos: EdUFSCar, 2010.

LAKOFF, G.; JOHNSON, M. Metáforas da vida cotidiana. Campinas: Mercado de Letras, 2002.

MERLEAU-PONTY, M. Fenomenologia da percepção. Tradução Carlos Alberto Ribeiro de Moura. São Paulo: Martins Fontes, 1999.

MARINI, G. D.; TOFFOLO, R. B. G. O tratado dos objetos musicais de Pierre Schaeffer revisitado pela fenomenologia de Merleau-Ponty. In: ENCONTRO DE PESQUISA EM MÚSICA - EPEM, 4., 2009, Maringá. Anais... Maringá: Universidade Estadual de Maringá, 2009.

TARDIF, M. Saberes profissionais dos professores e conhecimentos universitários: elementos para uma epistemologia da prática profissional dos professores e suas consequências em relação à formação para o magistério. Revista Brasileira de Educação, São Paulo, n. 13, p. 5-24, 2000.

TARDIF, M.; LESSARD, C.; LAHAYE, L. Os professores face ao saber: esboço de uma problemática docente. Teoria \& Educação, Porto Alegre, n. 4, p. 2015-233, 1991.

TURNER, V. From ritual to theatre: the human seriousness of play. New York: PAJ Publications, 1982.

VARELA, F. J.; THOMPSON, E.; ROSCH, E. Mente incorporada: ciência cognitiva e experiência humana. Porto Alegre: Artmed, 2003.

Recebido em 15/09/2017

Aprovado em 24/11/2017

Publicado em 03/05/2018 